\title{
Portinari e a arte social
}

ANNATERESA FABRIS*

\begin{abstract}
Resumo: O interesse pela pintura mural suscitou várias tomadas de posição no século $X X$, dentre elas, a defesa da difusão em ampla escala de imagens eivadas do compromisso do artista para com o próprio tempo e o próprio povo. No conjunto dos "ciclos econômicos", Portinari demonstra que é possível "narrar uma história" sem aderir à versão oficial, apresentando uma visão crítica da sociedade brasileira a partir do tema nuclear do trabalho.
\end{abstract}

\begin{abstract}
The interest in mural painting has resulted in many decision-makings in the 20th Century, among them the defense of large scale broadcasting of images shot through with the commitment of the artist with his own time and people. In the set of "economical cycles", Portinari demonstrates that it is possible to "narrate a story" without the attachment to the official version, presenting a critical view of the Brazilian society from the nuclear theme of work.
\end{abstract}

Palavras-chave: Portinari. Arte social. Muralismo.

Key words: Portinari. Social art. Muralism.

No conjunto dos "ciclos econômicos" (Ministério da Educação e Saúde), Portinari demonstra como é possível "narrar uma história" sem aderir à visão oficial, e sim apresentando uma visão crítica da sociedade brasileira contemporânea a partir de um tema nuclear como o trabalho.

Na primavera de 1936, a Casa da Cultura de Paris - fundada por Louis Aragon e Vaillant-Couturier - organiza dois debates sobre as relações entre arte, realidade contemporânea e possibilidades de transformação da sociedade, publicados em julho sob o título de A querela do realismo. Alinhados contra o estetismo, os participantes dos debates propõem duas soluções: uma arte decididamente pública, que fuja da especulação, ou uma arte mais

Professora da Escola de Comunicação e Artes da USP e Pesquisadora do CNPq.

Estudos Ibero-Americanos. PUCRS, v. XXXI, n. 2, p. 79-103, dezembro 2005 
acessível, que recuse o esoterismo e o preciocismo, isto é, uma arte para todos como princípio geral. ${ }^{1}$

Entre os defensores da primeira possibilidade está Fernand Léger, que ao individualismo do Renascimento contrapõe a idéia de "uma arte mural coletiva popular atual". Ao propor uma arte coletiva, o pintor, entretanto, não está pensando na renovação do conceito tradicional de realismo. O "novo realismo" defendido por ele deita raízes

na própria vida moderna, em seus fenômenos constantes, na influência dos objetos fabricados e geométricos, numa transposição em que a imaginação e o real se cruzam e se confundem, mas da qual foi banido todo sentimentalismo literário e descritivo, toda dramatização que sublinhe outras direções poéticas ou livrescas. ${ }^{2}$

Acreditando que a pintura figurativa não tinha condições de concorrer com aqueles "gigantescos mecanismos modernos" que se chamavam cinema, rádio, montagem fotográfica e publicidade, Léger confia a realização de seu projeto a uma arte "apaziguadora e interior", cuja matéria-prima seria a cor, capaz de "exaltar os sentimentos de ação ao infinito", de "manifestar a intensidade da vida sob todos os ângulos". ${ }^{3}$

Se as bases do novo realismo estavam no cotidiano - na linguagem popular, "forma móvel e sempre nova"; nas vitrinas das lojas "onde o objeto isolado detém e seduz o comprador" 4 - é na aliança da pintura com a arquitetura que Léger aposta para configurar um verdadeiro programa de arte coletiva. Não se tratava de uma aposta teórica, uma vez que o artista tivera oportunidade de realizar experiências de integração de pintura e arquitetura desde 1925. Naquele ano, apresentara na Exposição de Artes Decorativas de Paris "umas coisas abstratas, de cores puras, extremamente retangulares", 5 despertando a atenção do arquiteto belga Robert Mallet-Stevens, autor do Pavilhão do Turismo em colaboração com os escultores Jan e Joël Martel.

A Exposição de 1925 havia posto fim ao "cenário arquitetônico 1900", confrontando os arquitetos com a parede "branca e nua".

1 FAUCHEREAU, Serge. Les années 1936. In: La querelle du réalisme. Paris: Éditions Cercle d'Art, 1987, p. 24. Participam dos debates: Jean Lurçat, Marcel Gromaire, Edouard Goerg, Louis Aragon, Küss, Fernand Léger, Le Corbusier, André Lhote, Jean Labasque e Jean Cassou.

2 La querelle du réalisme. Op. cit., p. 104-105.

Ibid., p. 106-107.

Ibid., p. 107.

5 LÉGER, Fernand. Funções da pintura. São Paulo: Difusão Européia do Livro, s.d., p. 105. 
Léger propõe transformar "esse dispositivo de expectativa" num "novo espaço", a partir da introdução de elementos cromáticos, que deveriam gerar uma "parede elástica". O pintor não deixa de arrolar elementos para defender sua idéia de um novo espaço:

[...] se, numa parede se pinta um terço da área com uma cor diferente dos outros dois terços, a relação visual, do ponto de vista da distância entre nós e a parede, altera-se. Cria-se uma outra distância, melhor, um jogo de distâncias: se uma parte da parede é amarela e a outra azul, por exemplo, o amarelo recua e o azul avança.

É uma espécie de lei: as cores avançam ou recuam, do ponto de vista sensorial. Naturalmente, se se destrói a superfície habitável, aquilo a que chamo o retângulo habitável, cria-se um outro retângulo, sem limite físico e não mensurável. ${ }^{6}$

Além das paredes coloridas, o artista pode colaborar com a arquitetura através de decorações com cores livres. Léger prefere o termo livre a abstrato, pois acredita que a cor "é verdadeira, realista, emotiva em si própria, [...]; vale por si, como uma sinfonia musical, é uma sinfonia visual; harmoniosa ou violenta, deve, de qualquer modo, ser aceita. Aliás, as multidões modernas estão já acordadas para isso, já habituadas, pelos cartazes, pelas vitrinas, pelos objetos apresentados isoladamente no espaço". Ao perder "a moldura, a dimensão pequena, a qualidade móvel e individual", a pintura mural de cores livres tem condições de "destruir a morna sobriedade de certas obras de arquitetura", tais como estações ferroviárias, grandes espaços públicos, fábricas. ${ }^{7}$

A problemática social que permeia o discurso de Léger, atento à configuração de uma "ordem plástica racional" por intermédio da cor, elemento presente na vida cotidiana de cada pessoa e passível de enfrentar "a desordem publicitária que devora as paredes", 8 está presente também na intervenção de Le Corbusier em 1936. Ao refletir sobre o destino da pintura, o arquiteto considera que seus objetivos históricos não são mais congeniais aos tempos modernos, suplantados que foram pelas imagens produzidas pelo cinema, pelas revistas e pela imprensa diária. Diante dessa reviravolta no estatuto da imagem, Le Corbusier enxerga uma solução plausível para a pintura: integrar-se na arquitetura moderna não como decoração, mas com "um sentido suficiente da realidade presente". É por isso que prefere chamar a arte derivada da revolução cubista de "concreta", pois lhe reconhece um realismo interi-

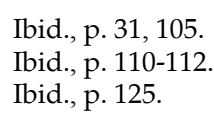


or, que se organiza por "camadas profundas em equilíbrio orgânico". Polêmico em relação à tese da abstração defendida por Worringer, o arquiteto estabelece um paralelo entre a arte e a espiritualidade da França, ambas dotadas de "uma objetividade profunda". Embora não chegue a definir claramente de que maneira seria possível estabelecer "um conjunto de alta harmonia", Le Corbusier defende a possibilidade de um encontro entre arquitetura e pintura. Discorda, entretanto, de Léger sobre a policromia enquanto prerrogativa pictórica por considerá-la própria da arquitetura. Tirando partido das "necessidades orgânicas" da planta moderna, ele mesmo percebera ser possível "disciplinar os tumultos pela cor, criar o espaço lírico, realizar a classificação, ampliar as dimensões, fazer explodir com a alegria o sentimento arquitetônico". .9

A postura de Léger e Le Corbusier é, porém, minoritária no âmbito do debate que, com diferentes matizes, tem como alvos diretos a abstração, o mito da originalidade e a desumanização, perseguidos pelas vertentes vanguardistas do começo do século XX. A tomada de posição contra este último aspecto pode ser exemplificada por uma frase de André Lhote, que prega "a volta ao homem, reclamando violentamente um fumante na extremidade do eterno cachimbo cubista ou ainda braços inspirados em volta da obsessiva guitarra insonora". ${ }^{10}$

Nem por isso Lhote adere a uma concepção trivial de realismo: não só localiza em Cézanne o artista que realizou "a representação mais profunda do homem", como o defende da visão corrente entre os intelectuais de esquerda de que suas obras não passavam de "exercícios vazios, um tanto burgueses". À "fixação das formas normais dos seres e das coisas", contrapõe um argumento qualitativo, alicerçado no domínio técnico e em novos modos de visão:

É necessário impor a qualidade à massa, e ter a coragem de responderlhe, se pedir anedotas, [...] que essas histórias pintadas, para alcançarem a qualidade, devem ser transpostas de maneira a transtornar todos os seus habituais modos de ver. Numa palavra, deve-se persuadir esse público de amanhã de que toda representação dele mesmo [...] não será autêntica, se não for especificamente pictórica. ${ }^{11}$

Jean Lurçat defende uma concepção mais engajada de realismo, ao posicionar-se decididamente contra uma visão purista e elitista da pintura ("técnica refinada, que tem como único objetivo

La querelle du réalisme. Op. cit., p. 111-121.

$10 \quad$ Ibid, p. 127.

11 Ibid., p. 130-133. 
gozos e choques nervosos"), a transformação da arte em "reportagem colorida" e toda postura neutra em relação ao presente ("atitude de conforto"). Vendo no artista "um transformador de energia; um homem que usa uma certa perspectiva", Lurçat propõe uma concepção de arte como ação, atribuindo ao pintor realista a tarefa de "carregar sua obra com todo o arsenal dos sentimentos, das necessidades, das exigências do próprio tempo". Só assim deixaria de ser "um especialista orgulhoso dos próprios tiques" para converter-se num "criador ativo", num "colaborador no conjunto das funções sociais". ${ }^{2}$

A defesa mais extrema do realismo é feita por Louis Aragon, ferrenho opositor da abstração, na qual detecta a simples demonstração de problemas técnicos da pintura, dirigida antes aos próprios pintores do que ao público. Em desacordo com Lhote e Lurçat, críticos em relação às contribuições fotográficas no âmbito das artes plásticas, o escritor exorta os pintores a verem na imagem técnica "uma experiência humana" não desprezível, por localizar a fonte de um novo realismo na compreensão de suas possibilidades como auxiliar da pintura. Militante comunista ortodoxo, define o realismo como "resultado das forças humanas"; dá-lhe como objetivo a tradução consciente dos "homens, que não são detalhes da paisagem nem existem independentemente uns dos outros", visto serem "determinados [...] por relações sociais". O que significa que esse realismo seria ao mesmo tempo uma "expressão consciente das realidades sociais" e "parte integrante do combate que modificará essas realidades". 13

O tom assumido pela "querela do realismo" e a centralidade conferida ao tema têm sua razão de ser, se for lembrado o clima político-social do momento. A crise de 1929 tivera como conseqüência imediata um desemprego crônico, o que havia tornado mais agudo o confronto entre as classes sociais e propiciado greves constantes. Além disso, havia um clima de beligerância no ar, que logo se tornará realidade concreta na Espanha e na China. Os artistas franceses, à semelhança do que ocorria nos Estados Unidos, estavam enfrentando sérias dificuldades financeiras ou até mesmo o desemprego diante da retração do mercado e da falta de encomendas. ${ }^{14}$

\footnotetext{
Ibid., p. 52-53, 55-56.

4 Fachereau, Serge. Les années 36. Op. cit., p. 20; NEGRI, Antonello. Il realismo: dagli anni trenta agli anni ottanta. Roma-Bari: Laterza, 1994, p. 57.
} 
Provocada pela ruptura entre os surrealistas e outros escritores e artistas de esquerda durante o Congresso pela Defesa da Cultura (junho de 1935), a "querela do realismo" havia sido antecipada pela enquete "Para onde vai a pintura?", promovida pela revista Commune. Entre as várias respostas fornecidas à pergunta formulada pelo órgão da Associação dos Escritores e Artistas Revolucionários, publicadas em maio e junho de 1935, vale lembrar a do único artista latino-americano consultado, Antonio Berni. O pintor argentino defende enfaticamente "a realização de figuras de dimensões extraordinárias visíveis a uma grande distância", deixando claro seu interesse pelo muralismo. Para poder opor-se ao "individualismo", ao "idealismo burguês", à "arte purista para exposições", o pintor deveria "ir para a rua, ser realista, monumental". A pintura mural deveria ser colocada "em pontos estratégicos das grandes cidades [...] acessíveis às grandes massas dinâmicas dos tempos modernos" por ser "a arte por excelência da futura sociedade socialista". 15

Embora Berni defenda o muralismo na enquete da revista francesa, sua relação com essa problemática é um tanto complexa. Colaborador de David Alfaro Siqueiros na realização de um mural na casa de campo de Natalio Botana (1933), não deixa de ser crítico em relação à postura do artista mexicano, para quem o muralismo era a única possibilidade de arte revolucionária numa sociedade burguesa. Confrontado com a situação argentina posterior ao golpe de estado de 1930, que não oferecia nem encomendas nem muros aos artistas, Berni discorda da atitude radical de Siqueiros, propugnando a possibilidade de uma pintura social, voltada para a denúncia das injustiças e realizada em telas de grandes dimensões. ${ }^{16}$

Mesmo que nenhum artista brasileiro tenha participado da enquete de Commune, seus resultados não deixam de ser conhecidos entre nós, vindo a servir de mote para a conferência que Aníbal Machado realiza no Clube de Arte Moderna do Rio de Janeiro em outubro de 1935. Proferida no encerramento da $1^{a}$ Exposição Coletiva de Arte Social, a conferência de Machado outorga um significado duplamente positivo à iniciativa: demonstrar que já não existia mais "esta distância entre o povo e os artistas", bem como revelar "um novo estado da arte no Brasil, arte que já começa a refletir a fase atual da movimentação revolucionária de sua cultura

5 La querelle du réalisme. Op. cit., p. 265.

16 LÓPEZ ANAYA, Jorge. Historia del arte argentino. Buenos Aires: Emecé, 1997, p. 167168 . 
e consciência política nascente no seio de suas massas". Acreditando que os artistas teriam um papel a desempenhar "na vontade de libertação política e cultural do nosso povo", o escritor mineiro traça um vivo contraponto entre a mostra de arte social e as exposições convencionais. Se o público demonstrara interesse pela iniciativa do Clube de Cultura Moderna, fora porque se confrontara com "uma arte objetiva, realista, popular", capaz de retratar "a vida cotidiana do homem no seu meio e no seu tempo", bem distante daquelas "telas de um colorido luminoso [...], mas vazias de conteúdo humano", a exibirem "um bem-estar que é falso, [...] uma felicidade que é o privilégio triste de uma parcela mínima da sociedade". ${ }^{17}$

Machado encontra uma justificativa para o fato de a maior parte dos trabalhos expostos ser de natureza gráfica: o desenho e a gravura de há muito haviam se voltado "para a realidade cotidiana, para os costumes do povo, [...] para a reportagem social e para a sátira política", enquanto a pintura estava "passando por um transe difícil". É nesse contexto que surge a referência ao empreendimento da revista parisiense e o pleito em favor do desenvolvimento de uma pintura mural no Brasil:

Uma enquete de Commune, em França, mostrou que ela ou se refugia em si mesma, para morrer de esterilidade ou se enquadra dialeticamente na época, formando ao lado das forças que ajudam a transformação universal. Nesse sentido, a última exposição do grande pintor Portinari revelou, pelos temas e pela técnica, uma inclinação real para essa vertente. Portinari já está a caminho da pintura mural, e para esse caminho estamos certos que arrastará os seus discípulos. [...] Já é tempo de o Governo entregar aos verdadeiros artistas do País a decoração dos muros, para que neles se inscrevam as formas e símbolos que despertam o interesse das multidões, a exemplo do que se faz no México de Rivera, Orozco e Siqueiros. Só assim poderão os artistas devolver mais largamente às massas o que estas lhes oferecem em estado potencial. ${ }^{18}$

As referências a Portinari e aos muralistas mexicanos não são casuais. A segunda fase do muralismo no México, correspondente ao governo do general Lázaro Cárdenas (1934-1940), estava propiciando uma ampliação do público da pintura mural, uma vez que

17 Machado, Aníbal. Mostra de arte social. In: ANTELO, Raúl (Org.). Parque de diversões: Aníbal Machado. Belo Horizonte: Editora UFMG; Florianópolis: Editora UFSC, 1994, p. 149-150. Participam da exposição: Portinari, Di Cavalcanti, Hugo Adami, Waldemar da Costa, Ismael Nery, Oswaldo Goeldi, Tomás Santa Rosa, Paulo Werneck, Noêmia Mourão, Alberto Guignard, Carlos Leão.

18 Ibid., p. 151. 
as intervenções dos artistas deixavam de limitar-se aos edifícios públicos mais importantes para abarcarem mercados, escolas, fábricas e sindicatos. ${ }^{19}$ Quanto a Portinari, Machado retomava sinteticamente os argumentos utilizados por Mário de Andrade, Mário Pedrosa e Oswald de Andrade por ocasião da exposição do pintor em São Paulo em dezembro de 1934. Os três críticos haviam notado em algumas obras apresentadas na galeria Itá o encaminhamento do pintor para o muralismo, que pode ser resumido nas palavras de Pedrosa:

Com o afresco e a pintura mural moderna, a pintura marcha no sentido do curso histórico, isto é, para sua reintegração na grande arte totalitária, hierarquizada pela arquitetura, da sociedade socialista em gestação. Portinari já sente a força desta atração. Como se deu com Rivera, com a escola mexicana atual, aliás - a matéria social o espreita. A condição de sua genialidade está ali. ${ }^{20}$

Embora não excluindo o quadro de cavalete do horizonte de suas realizações, Portinari posicionava-se naquele momento a favor de uma expressão pública:

A pintura atual procura o muro. O seu espírito é sempre um espírito de classe em luta. Estou com os que acham que não há arte neutra. Mesmo sem nenhuma intenção do pintor, o quadro indica sempre um sentido social. ${ }^{21}$

Machado e Portinari não são vozes isoladas na defesa de uma arte social. Em 1928, numa série de gravuras em linóleo para o semanário Lo Spaghetto, Lívio Abramo já colocava no centro de seus interesses a figura do operário. Tratava-se de composições regidas, via de regra, por uma simplificação extrema da linguagem, nas quais começava a insinuar-se um princípio de deformação expressionista. Militante comunista entre 1930 e 1932 e, em seguida, adepto da ala esquerda do Partido Socialista Brasileiro, o gravador realiza naquele período um conjunto de trabalhos francamente expressionistas que, de acordo com Mário Pedrosa, transpunham "para a xilo o tema da luta de classes". 22 Se a economia formal continua sendo um princípio condutor da obra de Abramo, o aspecto expressionista localiza-se sobretudo nos cortes rápi-

NEGRI, Antonello. Il realismo: dagli anni trenta agli anni ottanta. Op. cit., p. 12.

20 PEDROSA, Mário. Impressões de Portinari. Diário da Noite, São Paulo, 7 dez. 1934.

21 "Portinari, paulista de Brodowski, vae mostrar a S. Paulo os seus últimos trabalhos". Folha da Noite, São Paulo, 20 nov. 1934. Vide também: "Exposição de pintura Candido Portinari". Diário de S. Paulo, 21 nov. 1934.

22 PEDROSA, Mário. Entre a Semana e as Bienais. In: AMARAL, Aracy (Org.). Mundo, homem, arte em crise. São Paulo: Perspectiva, 1975, p. 278. 
dos e decididos de goiva que conferem um caráter de tensão controlada a suas gravuras.

Na conferência "Käthe Kollwitz e seu modo vermelho de perceber a vida", realizada no Clube de Arte Moderna de São Paulo por ocasião da exposição da gravadora alemã em 1933, Pedrosa inaugura "um novo tempo" na crítica brasileira, ao propor uma interpretação marxista do fenômeno artístico, não alinhada ao sectarismo que se impusera no Congresso de Karkov (1934) e que prenunciava a linha jdanovista. Sob a égide de Marx, Engels, Hegel, Grosse e Semper, ${ }^{23}$ Pedrosa detecta duas vertentes principais no campo artístico da atualidade: a arte daqueles criadores interessados tão somente na "segunda natureza superposta à primitiva que é a nossa natureza moderna e mecânica - a técnica" e, por isso mesmo, "desligados completamente da sociedade", estiolados "num irrespirável individualismo egocentrista a serviço de uma casta parasitária ou no hermetismo diletante para meia dúzia de iniciados"; e a expressão dos artistas sociais, que "se aproximam do proletariado e, numa antecipação intuitiva da sensibilidade, divisam a síntese futura entre a natureza e a sociedade, destituída afinal dos idealismos deformadores e das convulsões místicas das carcomidas mitologias". ${ }^{24}$

Fiel à própria classe, Käthe Kollwitz é apresentada como um paradigma da arte social. Uma arte "partidária e tendenciosa", cujo destino não está na própria arte, mas "socialmente no proletariado". Uma arte, portanto, instrumental, mas dotada de uma "assombrosa universalização", por aspirar a "um novo humanismo superior, um autêntico e novo classicismo surgido dramática e espontaneamente da própria vida". ${ }^{25}$

Também de 1933 é o artigo "A exposição de Tarsila, a nossa época e arte", publicado por Di Cavalcanti no Diário Carioca. Motivado pela exposição de Tarsila do Amaral no Palace Hotel do Rio de Janeiro, na qual estavam sendo apresentadas obras emblemáticas como Operários (1933) e $2^{a}$ classe (1933), o artigo do pintor é uma vigorosa tomada de posição contra a arte neutra, inspirada sobretudo pelo ideário de Bogdanov. Advogando o fim da separa-

23 AMARAL, Aracy. Arte para quê: a preocupação social na arte brasileira, 1939-1970. São Paulo: Nobel, 1984, p. 38; ARANTES, Otília Beatriz Fiori. Mário Pedrosa: itinerário crítico. São Paulo: Scritta Editorial, 1991, p. 9-11. Ao ser publicada em capítulos no jornal antifascista $O$ homem livre (julho de 1933), a conferência recebe o título de "As tendências sociais da arte e Käthe Kollwitz".

24 PEDROSA, Mário. As tendências sociais da arte e Käthe Kollwitz. In: ARANTES, Otília (Org.). Política das artes: textos escolhidos I. São Paulo: EDUSP, 1995, p. 46-48.

25 Ibid., p. 49. 
ção entre artista e público, Di Cavalcanti defende a necessidade de uma arte revolucionária na sociedade contemporânea. Num tom excitado, advoga a ida do artista às massas "com o coração aberto para se fortalecer e para se glorificar", para "fazer entrar em cena esse enorme e novo personagem tal qual como ele é, com as finalidades que ele possui, nas mãos e no cérebro". O realismo defendido pelo pintor concentra-se em três eixos: "ditadura do social, emprego do individual a serviço do coletivo, demolição e marcha revolucionária". ${ }^{26}$

Não imbuída do ideário marxista, a defesa de uma arte engajada havia sido feita naquele mesmo ano por Mário de Andrade no catálogo da exposição organizada pela Sociedade Pró-Arte Moderna. O escritor que, dois anos antes, havia criticado o público interessado naquilo que "o artista possui não de funcional e humano, mas de prazer floral, puramente individualista", reclama na exposição da SPAM a falta de

criadores de ordem social. É uma falha sensível essa ausência de arte social entre nós [...]. Esperemos que em exposições futuras, o ecletismo natural de Spam apareça completado com pintores que se resolvam a tomar posição qualificada, não apenas diante da natureza, mas da vida também. ${ }^{27}$

A presença de um debate bastante acalorado sobre a função social da arte, no qual Portinari se engaja sobretudo com suas obras que têm como tema o trabalho rural, o cotidiano nas favelas cariocas, o retirante nordestino e reminiscências da infância, incidindo na caracterização de dois tipos - o negro e o mulato -, não parece ser alheia à decisão do ministro Gustavo Capanema de outorgar ao pintor de Brodósqui a realização dos afrescos dos ciclos econômicos no Ministério da Educação e Saúde Pública, criado em dezembro de 1930, logo após a vitória da revolução que levara ao governo Getúlio Vargas. Se for lembrado que Capanema atribuía ao ministério do qual era titular a tarefa de "preparar, compor e afeiçoar o homem do Brasil", e que conferia à cultura o papel de

26 DI CAVALCANTI. A exposição de Tarsila, a nossa época e a arte". In: AMARAL, Aracy. Tarsila: sua obra e seu tempo. São Paulo: Perspectiva/EDUSP, 1975, v. 1, p. 479.

27 ANDRADE, Mário de. O castigo de ser - III. In: Táxi e crônicas no Diário Nacional. São Paulo: Duas Cidades/Secretaria de Cultura, Ciência e Tecnologia, 1976, p. 469; Primeira exposição de arte moderna da SPAM. São Paulo, 1933, s.p. Participam da exposição: Anita Malfatti, Victor Brecheret, Lasar Segall, Tarsila do Amaral, Antônio Gomide, John Graz, Regina Graz, Hugo Adami, Vittorio Gobbis, Paulo Rossi Osir, Ester Bessel, Moussia Pinto Alves, Arnaldo Barbosa, além de alguns artistas da Escola de Paris, cujas obras constavam de coleções particulares paulistas. 
articular "a nítida e impressiva presença do homem" diante da natureza e das "forças circundantes", ${ }^{28}$ não será difícil compreender a razão que o leva a privilegiar o tema dos ciclos econômicos.

$\mathrm{O}$ quadro histórico que deveria servir de pano de fundo à configuração das atividades econômicas que haviam contribuído na construção de uma nova civilização no Brasil é fornecido a Portinari por Rodolfo Garcia e Afonso Arinos de Mello Franco. Garcia abastece o pintor com excertos de quatro obras - História geral do Brasil antes de sua separação e independência de Portugal (1854-1857), de Francisco Adolfo de Varnhagen; Cultura e opulência do Brasil (1711), de André João Antonil; Travels in Brazil (1816), de Henry Koster; Capítulos de história colonial, 1500-1800 (1907), de João Capistrano de Abreu. ${ }^{29}$ A seleção de Garcia é bastante significativa em suas escolhas, que incluem a configuração da idéia de nação de maneira factual (Varnhagen), observações sobre a economia da colônia no século XVIII (Antonil), considerações de um viajante inglês sobre a agricultura e a pecuária no começo do século XIX (Koster) e uma abordagem analítica do passado colonial, cujos eixos fundamentais eram a conquista da terra, o surgimento de uma sociedade local e o amadurecimento do nativismo (Capistrano de Abreu).

A não ser no caso de Varnhagen, as demais obras selecionadas por Garcia incidem diretamente nos aspectos econômicos do Brasil colonial. Cultura e opulência do Brasil articula-se em quatro partes que tratam do cultivo e do refino do açúcar, da lavoura e do preparo do tabaco, da mineração e da criação do gado. Em Travels in Brazil, Koster, que chegara ao país em 1809 e percorrera as províncias da Paraíba, Maranhão e Pernambuco, tornando-se dono de um engenho na última, fornece informações sobre a agricultura do período (cultivo da cana de açúcar e do algodão), a atividade pecuária no sertão, além de alguns dados sobre o tabaco, o cacau, o café, a carnaúba e o transporte do pau-brasil para o litoral. $\mathrm{O}$ trabalho de Capistrano de Abreu, alicerçado em elementos geográficos, etnográficos, econômicos e sociais, apresenta um quadro bastante original do passado do Brasil ao levar em conta "o povo durante três séculos capado e recapado, sangrado e ressangrado", por

28 LISSOVSKY, Maurício; SÁ, Paulo Sérgio Moraes de. O novo em construção: o edifício-sede do Ministério da Educação e Saúde e a disputa do espaço arquitetural nos anos 1930. In: GOMES, Angela de Castro (Org.). Capanema: o ministro e seu ministério. Rio de Janeiro: Editora FGV/Universidade São Francisco, 2000, p. 50.

29 PIAZZA, Maria de Fátima Fontes. Os afrescos nos trópicos: Portinari e o mecenato Capanema. Florianópolis: Centro de Filosofia e Ciências Humanas/UFSC, 2003, p. 65 (mimeo). 
intermédio de uma história livre, em grande parte, da seriação de datas e nomes. ${ }^{30}$

Deve-se a Afonso Arinos de Mello Franco a concepção dos ciclos econômicos, apresentada no programa de História do Brasil da Universidade do Distrito Federal. Ao aceitar o convite formulado pelo reitor Afonso Pena Jr. em 1936, Arinos propõe dividir a história do país "em ciclos econômicos, cronologicamente distribuídos: o do pau-brasil; o do gado; o do ouro; o do café e, finalmente, o da indústria". Dois anos mais tarde, tais idéias serão divulgadas em Sintese da história econômica no Brasil, na qual são analisados o pau-brasil (e seus comércios ancilares), o açúcar, o tabaco, a criação de gado, a mineração (ouro e diamante), o café e o ciclo industrial. Em 1937, Roberto Cochrane Simonsen havia publicado História econômica do Brasil (1500-1820), corroborando o interesse que essa nova interpretação historiográfica estava despertando no meio intelectual. Inspirado no historiador português João Lúcio de Azevedo, autor de Épocas de Portugal econômico (1929), Simonsen estuda em sua obra o aproveitamento econômico das terras de Santa Cruz, dando um destaque particular ao açúcar, à pecuária (como fator de conquista do território e, logo, da formação unitária do país), à mineração e à ocupação do Amazonas. ${ }^{31}$

Confrontado com um quadro historiográfico, no qual a visão política e os grandes vultos não cabem, o que faz Portinari? Propõe a Capanema sua "pintura de camponês", ${ }^{2}$ isto é, insere o tema dos ciclos econômicos no âmbito interno de sua poética, descartando o viés historicista implícito na escolha do ministro e configurando uma visão do Brasil cujo epicentro é o trabalhador. Afirmar que o pintor inclui a encomenda ministerial no interior de sua poética pessoal, não implica dizer que não tenha levado em conta o tema e o roteiro propostos. Entre 1936 e 1938, Portinari executa centenas de estudos em diferentes técnicas (têmpera, carvão, crayon, guache, aquarela), além de realizar desenhos em tamanho natural para transporte na parede, contando com o auxílio de um grupo de alunos do Instituto de Arte da Universidade do Distrito Federal,

30 RODRIGUES, José Honório. Prefácio. In: ABREU, João Capistrano de. Capítulos de história colonial, 1500-1800. Belo Horizonte: Itatiaia; São Paulo: Publifolha, 2000, p. 19.

31 PIAZZA, Maria de Fátima Fontes. Os afrescos nos trópicos: Portinari e o mecenato Capanema. Op. cit., p. 71-74, 293-294. Num depoimento de 1977, Arinos fala de "ciclos predominantes” (pau-brasil, açúcar, gado, mineração, café, industrialização) e de "culturas ancilares" (cacau, borracha, mate, etc.). Cf.: FRANCO, Afonso Arinos de Mello. Os ciclos econômicos do Ministério da Educação e Cultura. In: CAMARGO, Ralph (Org.). Portinari desenhista. Rio de Janeiro: Museu Nacional de Belas Artes; São Paulo: Museu de Arte de São Paulo, 1978, p. 89.

32 DIONÍSIO, Mário. Portinari. s.l.: Artis, 1963, p. 10. 
no qual ministrava aulas de pintura mural e de cavalete (Inês Correia da Costa, Rubens Cassa, Roberto Burle Max), e de Enrico Bianco, que chega ao Rio de Janeiro no final de 1937. A fim de conferir credibilidade às diversas representações do trabalho, o artista não deixa de realizar viagens pelo país: observa os garimpeiros em Mariana e Ouro Preto; documenta as atividades nos altos-fornos da Companhia Belgo-Mineira em Sabará. Entre 1939 e 1944, é realizado o trabalho pictórico, para o qual Portinari conta com a colaboração de Diana Barberi, Héris Guimarães, Bianco e de Eugênio Sigaud (somente durante um mês). Seu viés de pesquisador incansável manifesta-se mais uma vez: atento a todos os detalhes, analisa a cal e a areia que servirão de revestimento às paredes, faz experiências com as terras brasileiras, o que lhe permite lançar mão de novas cores, importa tintas especiais. ${ }^{33}$

A divulgação dos desenhos preparatórios, caracterizados por um tom bastante realista, provoca uma severa crítica de Oswald de Andrade, que detecta no empreendimento do Ministério a volta do "velho produto da Escola de Belas-Artes", ao qual contrapõe o bom artista dos primeiros anos da década de 1930. Não contente em acusar o pintor de utilizar "recursos passadistas e primários", o escritor chega a falar em plágio, quando afirma que este se pôs "a virtuosar pés, mãos, cabeças copiadas de Rivera ou de documentos coloniais". ${ }^{34}$ A crítica parece ter calado fundo em Portinari, pois na execução dos murais adota uma série de recursos que negam a visão realista que estava sendo associada ao conjunto: exclusão de todo detalhe desnecessário, uso de deformações e de alguns fundos "abstratos", tratamento das figuras por cores chapadas e massas cromáticas, entre outros. O artista atribui as modificações ocorridas na passagem do desenho à parede às condições de iluminação da sala, que teriam motivado transposições formais e cromáticas, ${ }^{35}$ mas é possível pensar que a economia de meios exibida nos afrescos tenha derivado sobretudo de uma exata percepção da natureza da pintura mural que requeria uma maior rapidez de execução.

Estruturado à guisa de um friso circundante colocado no alto das paredes da ante-sala do gabinete do ministro, o conjunto dos ciclos econômicos se articula de maneira cronológica, embora não rigidamente. Na parede esquerda estão localizadas as representa-

33 BARROS, Geraldo Mendes. O Palácio da Educação apresentará grandiosa decoração a fresco. Correio Paulistano, São Paulo, 20 ago. 1938.

34 ANDRADE, Oswald de. De literatura: para comemorar Machado de Assis. Meio-Dia, Rio de Janeiro, 10 maio 1939.

35 ANTONIO BENTO. Portinari. Rio de Janeiro: Léo Christiano Editorial, 1980, p. 79. 
ções do pau-brasil, da cana de açúcar e do gado. A parede central é ocupada por garimpo, fumo, algodão, erva mate, café e cacau. Na parede direita observam-se as cenas relativas a ferro, borracha e carnaúba. Embora as várias atividades econômicas sejam facilmente reconhecíveis em virtude dos atributos presentes nas cenas, $\mathrm{o}$ que se impõe ao observador é o caráter coeso do conjunto, determinado, antes de tudo, pela unidade cromática e formal que Portinari conseguiu lhe infundir.

Em termos cromáticos, o conjunto exibe tons quase sempre escuros nos fundos, articulados em diferentes áreas de cor predominantemente frias. As figuras dos trabalhadores, geralmente vestidos de branco, criam zonas luminosas em contraste com o fundo, mas se trata de uma luminosidade anti-realista em virtude das tonalidades embaçadas e dos focos de luz diferenciados que o artista lança sobre cada painel. Em termos formais, o caráter injusto da crítica de Oswald de Andrade é ainda mais evidente. Se é inegável que o muralismo mexicano está na base do empreendimento brasileiro, essa proximidade deve ser encarada como um exemplo moral, não como uma cópia de soluções formais, uma vez que Portinari opta por uma composição dinamicamente controlada, articulada por planos geométricos que ordenam racionalmente $o$ espaço, bem diferente do horror vacui exibido pelos murais dos artistas mexicanos, cujas seqüências de natureza cinematográfica atualizam, segundo Antonello Negri, o conceito naturalista de ciclo. ${ }^{36}$

A mágoa de Portinari com uma comparação que considerava injusta transparece numa carta a Mário de Andrade, na qual reporta seu interesse em pintar "fotograficamente" a realidade circundante a um tipo de visão enraizado na infância, que o levava a tomar partido "não na maneira mexicana mas na minha maneira de Brodósqui". Na resposta, o amigo estabelece um claro contraponto entre os dois tipos de realização e formula um conselho:

Não precisa combater com os mexicanos, não. Combatem, são nobres, também merecem todo o nosso respeito e entusiasmo. Mas não há dúvida que, na exacerbação do combate, enfraqueceram a qualidade plástica das obras deles que se ressentem de um desequilíbrio forte entre valor plástico e valor espiritual. [...] E tenho a certeza que você está mais certo, no seu poderoso equilíbrio. ${ }^{37}$

NEGRI, Antonello. Il realismo: dagli anni trenta agli anni ottanta Op. cit., p. 7.

7 Carta de Portinari a Mário de Andrade (Rio de Janeiro, 22 out. 1944); Carta de Mário de Andrade a Portinari (São Paulo, 25 out. 1944). In: FABRIS, Annateresa (Org.). Por- 
O que Mário de Andrade denomina "poderoso equilíbrio" está presente nos vários recursos estilísticos e compositivos de que se vale o pintor, a começar pelo sentido de síntese que permeia o conjunto. Se forem levadas em consideração as fontes bibliográficas propostas a Portinari, o significado da síntese buscada por ele se torna ainda mais evidente. Em Cultura e opulência do Brasil, Antonil apresenta não apenas longas considerações de ordem técnica sobre cada modalidade de atividade econômica analisada, bem como discute as condições de trabalho e produção, fornecendo detalhes minuciosos sobre cada etapa e dados estatísticos a respeito do comércio e da exportação dos principais recursos econômicos do país no período enfocado. A comparação entre o painel Cana de açúcar e as considerações de Antonil sobre a atividade pode fornecer uma idéia do método empregado por Portinari. Enquanto o autor descreve todas as etapas da produção - da escolha do terreno ao refino e posterior comercialização -, o pintor escolhe um único momento, o do corte da cana, concentrando-se em duas figuras de trabalhadores, o cortador e o carregador. Na escolha dessas duas figuras, Portinari comete um pequeno desvio histórico: exclui da atividade a figura da escrava, encarregada de ajuntar as canas limpas e de amarrar os feixes que seriam levados ao engenho em carros de boi. ${ }^{38} \mathrm{O}$ mesmo caráter sintético está presente na interpretação que Portinari faz das demais atividades descritas no livro de Antonil. Se o autor esclarecia que a "fábrica e cultura do tabaco" envolviam uma grande quantidade de indivíduos "grandes e pequenos, homens e mulheres, feitores e servos" - e descrevia as atividades de cada trabalhador, ${ }^{39}$ Portinari opera uma abstração das diferentes etapas de produção. O painel Fumo, de fato, apresenta um trabalhador de costas levemente inclinado, sem que seja possível determinar a natureza de sua tarefa, acompanhado por um outro trabalhador flagrado no momento em que está bebendo de uma cabaça, cada um deles observado por uma figura feminina. Uma outra figura feminina ocupa o primeiro plano da composição, aparentemente absorvida na contemplação da planta

tinari, amico mio: cartas de Mário de Andrade a Cândido Portinari. Campinas: Mercado de Letras/Editores Associados/Projeto Portinari, 1995, p. 144.

38 Antonil, André João. Cultura e opulência do Brasil. Belo Horizonte: Itatiaia; São Paulo: EDUSP, 1982, p. 106. O mesmo pode ser dito em relação a Koster, que descreve detalhadamente os canaviais, as terras apropriadas ao cultivo, as atividades desenvolvidas no engenho, na casa das caldeiras, na destilaria e o "estoque" humano e animal necessário ao empreendimento. Cf.: Koster, Henry. Viagens ao Nordeste do Brasil. São Paulo: Companhia Editora Nacional, 1942, p. 421-444.

39 ANTONIL, André João. Cultura e opulência do Brasil. Op. cit., p. 153-154. 
que dá nome ao painel. contemplação da planta que dá nome ao painel.

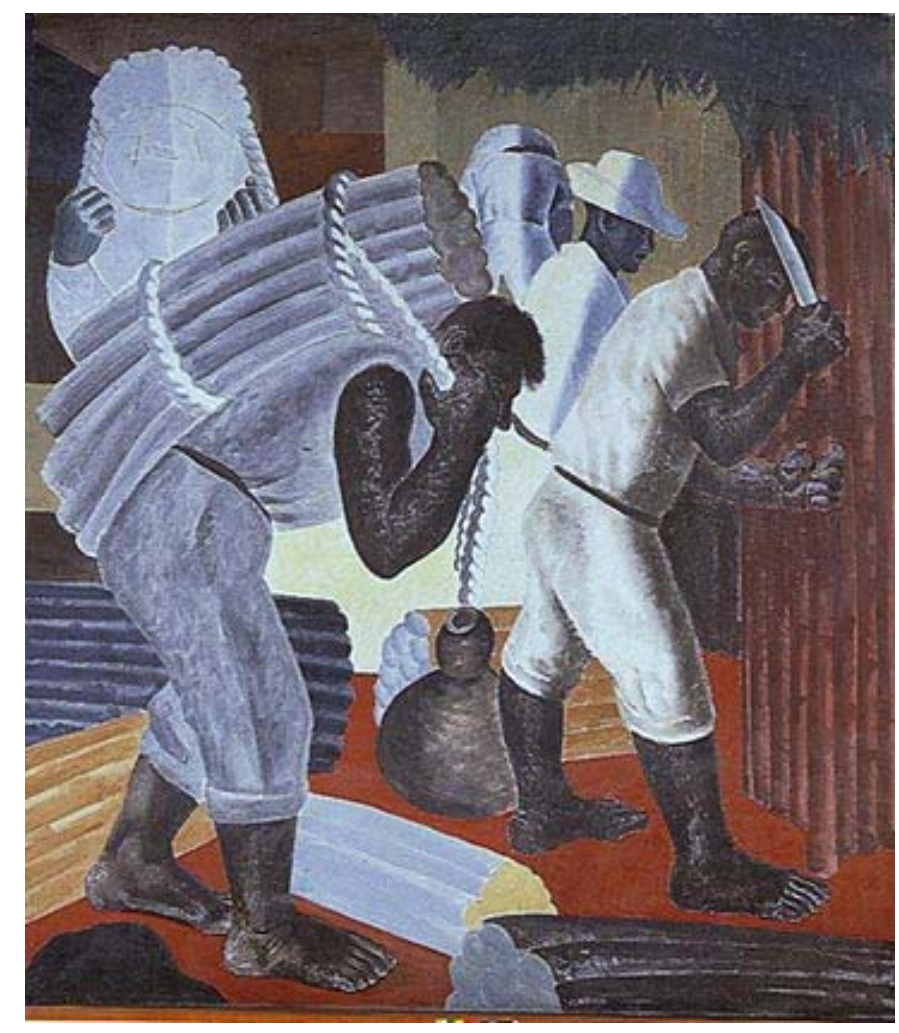

\section{Cana}

Pintura mural a afresco, Rio de Janeiro, RJ.

280 x 247 cm. Coleção Palácio Gustavo Capanema. Obra executada para decorar o salão de audiências, 1938. 


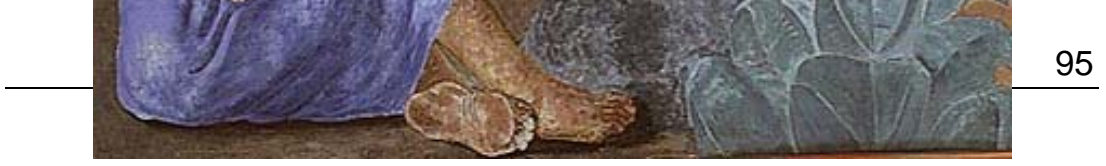

\section{Fumo}

Pintura mural a afresco, Rio de Janeiro, RJ.

280 x 294 cm. Coleção Palácio Gustavo Capanema. Obra executada para decorar o salão de audiências, 1938.

O sentido de síntese não é apenas visível no confronto entre a interpretação plástica e as fontes historiográficas que lhe serviram de base. Portinari reduz ao máximo os elementos exteriores à temática do trabalho: a ambiência natural não passa de alguns elementos referenciais, o mesmo acontecendo com alguns fundos arquitetônicos, que denotam a adoção de recursos utilizados pelos primitivos italianos. A ordenação interna dos painéis é também de caráter sintético. O pintor situa em cada cena poucas figuras gigantescas, cuja volumetria evoca a estatuária; confere-lhes uma gestualidade estática e essencial, confiando o efeito de dinamismo a um jogo de correspondências psicológicas; despoja quase todas as fisionomias de traços característicos, construindo os rostos por planos e formas geométricas; racionaliza ao extremo o espaço; articula a temporalidade da ação em vários momentos significativos, embora imobilizados como na maior parte das obras de uma de suas fontes visuais indiscutível, Piero della Francesca.

Essa estrutura, inspirada essencialmente nas lições renascentistas, é eivada de deformações anatômicas que, entretanto, não colocam em risco a sobriedade da composição. As figuras, longe de apresentarem um tratamento realista, são sintetizadas em seus traços essenciais e determinadas volumetricamente pela cor, inserindo-se na topologia espacial, igualmente construída por intermédio de manchas cromáticas, de maneira a criar uma tensão equilibrada.

Além da sobriedade da estruturação plástica, os painéis dos ciclos econômicos chamam a atenção pelo fato de a representação do trabalhador incidir quase sempre na figura do negro, contradizendo em parte as fontes históricas e dando ao escravo um destaque que ele nem sempre conseguia nos estudos especializados. Se Antonil reconhece a contribuição do negro como fator decisivo da riqueza nacional, chegando a condoer-se da sorte dos que trabalhavam na casa das fornalhas - "cárcere de fogo e fumo perpétuo", a evocar vulcões como o Vesúvio e o Etna, e quase o Purgatório e o Inferno -, não deixa de lembrar que outras etnias se destacaram nessa tarefa: brancos e "muitos índios" no caso da mineração, que atraiu todo tipo de gente ("homens e mulheres, moços e velhos, 
pobres e ricos, nobres e plebeus, seculares e clérigos, e religiosos de diversos institutos"), e na condução das boiadas pelo sertão. ${ }^{40}$

Koster, que oferece maiores informações a respeito do trabalho do escravo africano, destacando sua extenuação na casa das caldeiras durante o refino do açúcar e os perigos a que estava exposto na condução dos carros de boi, lembra a existência concomitante de homens livres em várias atividades ligadas à cana de açúcar e o caráter eminentemente mestiço do vaqueiro. ${ }^{41}$

Capistrano de Abreu, por sua vez, interessado em construir a história da nacionalidade brasileira enquanto "história do descobrimento, do desbravamento e do povoamento, sem determinismos geográficos ou raciais, e sem voluntarismos da ação humana" ${ }^{42}$ não confere ao escravo africano e a seus descendentes o devido destaque. Em Capitulos de história colonial, há poucas referências pontuais ao contributo do negro. $\mathrm{O}$ autor faz menção a ele quando lembra a legislação de 1680 que proibia a escravidão dos índios, substituídos por africanos, "mais fortes e mais próprios para a pesada labuta agrícola"; quando se refere à criação de gado e à cultura do tabaco; quando analisa a vida nas cidades costeiras, nas quais os escravos desempenhavam funções domésticas e outras ocupações convencionadas com os donos. Além de ser reduzida a poucas observações, a presença do africano é apresentada por um viés condescendente para com o regime escravagista, posto que Capistrano de Abreu assim caracteriza o escravo urbano: "Sua alegria nativa, seu otimismo persistente, sua sensualidade animal sofriam bem o cativeiro". 43

$40 \quad$ Ibid., p. 115, 167, 202.

41 Koster, Henry. Viagens ao Nordeste do Brasil. Op. cit., p. 207, 432, 443-444.

42 GOMES, Angela de Castro. História e historiadores: a política cultural do Estado Novo. Rio de Janeiro: Fundação Getúlio Vargas, 1996, p. 98.

43 ABREU, João Capistrano de. Capitulos de história colonial, 1500-1800. Belo Horizonte: Itatiaia; São Paulo: Publifolha, 2000, p. 147, 150, 154-155, 235. 


\section{Garimpo}

Pintura mural a afresco, Rio de Janeiro, RJ.

280 x 298 cm. Coleção Palácio Gustavo Capanema. Obra executada para decorar o salão de audiências, 1938.

Ao conceder primazia à figura do negro nos afrescos do Ministério da Educação e Saúde Pública, Portinari apresenta uma leitura particular do passado, que não vê como um objeto histórico inerte, uma vez que nele está enraizada uma situação presente que constitui o fulcro de sua operação artística. O negro, nesse contexto, não é apenas um protagonista histórico da constituição da nação brasileira. É, antes de tudo, uma figura ideológica, por cujo intermédio Portinari questiona a política populista proposta pelo governo Vargas, alicerçada no pacto entre capital e trabalho. A iconografia portinariana é bem significativa nesse sentido: a presença dominante do negro, que permite criar de imediato uma associação com o regime escravocrata, coloca em xeque a "mística do trabalho" propugnada por Vargas e a idéia interclassista a ela inerente, na medida em que apresenta uma única figura de trabalhador, empenhado desde cedo na construção da riqueza nacional. De maneira intuitiva, o pintor coloca no centro de sua representação uma problemática que Caio Prado Júnior havia esmiuçado em Evolução política do Brasil, publicado em 1933. Crítico em relação à historiografia oficial, Prado propõe uma nova maneira de estudar o Brasil a partir da interpretação materialista. Desse modo, as classes enquanto categoria analítica "emergem pela primeira vez nos horizontes da explicação da realidade social brasileira", ${ }^{44}$ rompendo com a visão monolítica que imperara até aquele momento. Ao excluir outros elementos do espaço produtivo dos painéis, Portinari remete de maneira discreta, mas não menos incisiva, à contradição entre o caráter social do trabalho e a propriedade privada dos meios de produção, idéia reforçada pela presença da figura do capataz, isto é, de um elemento fundamental na empresa capitalista, em Café e Erva mate. 45

44 MOTA, Carlos Guilherme. Ideologia da cultura brasileira: pontos de partida para uma revisão histórica. São Paulo: Ática, 1977, p. 28.

45 Para dados ulteriores, vide: FABRIS, Annateresa. Portinari, pintor social. São Paulo: Perspectiva/EDUSP, 1990, p. 124-131. Em relação ao capataz, Koster observa que a função era exercida quase sempre por um mulato livre, quando não por um escravo, "que exige maior trabalho e cuida mais rigorosamente daqueles que foram entregues ao seu comando". Cf.: KOSTER, Henry. Viagens ao Nordeste do Brasil. Op. cit., p. 516517. 
A presentificação da história empreendida por Portinari não deixa de ser destacada por Hoje, órgão do Partido Comunista Brasileiro, quando o pintor se lança a candidato para deputado federal por São Paulo em novembro de 1945:

Que são os murais do Ministério da Educação senão um poderoso documentário da nossa vida econômica atual ao qual o homem está em primeiro plano, esmagado pelo trabalho, recurso às ordens de um feitor de dedo estendido, de botas e esporas, em contraste com o operário de pé no chão?46

Analisando os painéis dos ciclos econômicos por esse prisma, é possível recuperar alguns aspectos do debate sobre o realismo que estava sendo realizado tanto na Europa quanto no Brasil. Portinari, de fato, pode ser visto como um artista que se mantém fiel à própria classe, do mesmo modo que a Käthe Kollwitz descrita por Mário Pedrosa. As categorias usadas pelo crítico na análise dessa faceta da gravadora alemã podem ser aplicadas ao artista brasileiro: provindo do meio rural, nem o triunfo pessoal nem os sucessivos encontros artísticos o afastam de uma linguagem realista, a mais apropriada para expressar sua visão crítica. A opção pelo realismo não deve ser reportada apenas a uma preferência artística, alinhada ao clima de volta à ordem que imperava na Europa no período em que o artista lá residiu entre fins dos anos 1920 e início da década sucessiva. A escolha de um vetor realista pode ser analisada nos mesmos moldes propostos por Louis Aragon no debate de 1936. Mesmo sem aderir aos ditames do realismo socialista, Portinari apresenta o trabalhador inserido na rede das relações sociais; por isso dá tanto destaque à sua figura, em detrimento da paisagem, e não o isola de um processo mais amplo, no qual desempenha um papel específico.

Os recursos estilísticos usados pelo artista - estrutura espelhada, em que a mesma figura executa sucessivamente o mesmo gesto produtivo (Borracha, Ferro, Fumo, Garimpo, Algodão, Paubrasil) e desdobramento da mesma figura em vários momentos da produção (Cacau, Café, Cana de açúcar, Gado, Pau-brasil) -, associados quase sempre ao tratamento prototípico das fisionomias remetem às idéias de "trabalho coletivo" e de "força produtiva coletiva"47 e, logo, às relações sociais que regem toda atividade econômica.

46 FACÓ, Rui; Santos, Rui. O pintor e militante comunista Portinari candidato a deputado federal por São Paulo na chapa do P.C.B. Hoje, São Paulo, 11 nov. 1945.

47 FABRIS, Annateresa. Portinari, pintor social. Op. cit., p. 127. 
O predomínio da figura humana sobre a paisagem, advogado por Aragon, está igualmente presente nos afrescos de Portinari não apenas em virtude da compreensão dos objetivos próprios da pintura mural, mas como conseqüência do amadurecimento de uma visão pictórica e social a um só tempo, oportunamente destacada por Pedrosa no artigo dedicado à primeira exposição do artista em São Paulo em 1934. A abolição da paisagem ou sua representação a partir de alguns índices iconográficos apenas referenciais faz com que o pintor dê toda concretude à figura do trabalhador, magnificada pela deformação e pelo agigantamento da mão e do pé.

As imagens de "trabalhadores com fisionomia forte e saudável" não respondem à estética política nacionalista do período, como afirma Daryle Williams. ${ }^{48}$ São, ao contrário, a resposta que Portinari dá à teoria da inferioridade racial, que ainda grassava na sociedade brasileira, por mais que o Estado Novo tenha impulsionado o debate sobre a mestiçagem como fator de integração sem conflitos. Bastaria lembrar alguns episódios para além da atuação pontual da Liga Brasileira de Higiene Mental e da Comissão Central Brasileira de Eugenia ao longo dos anos 1930. O primeiro deles diz respeito ao veto da inclusão de Café, a obra que consagrara Portinari no exterior, na Exposição Internacional de Paris em 1939, levando Santa Rosa a escrever que o país não queria se reconhecer na "representação de homens pretos e mulatos, na sua rude labuta, produzindo a riqueza nacional". O segundo envolve Caio Prado Jr. que, em Formação do Brasil contemporâneo (1942), comete um deslize significativo assinalado por Carlos Guilherme Mota. Ao analisar o sentido da colonização, o autor lembra o papel desempenhado pelo branco, "que reúne à natureza pródiga em recursos aproveitáveis para a produção de gêneros de grande valor comercial, o trabalho recrutado entre raças inferiores que domina: indígenas ou negros africanos importados". ${ }^{4}$

A solidez que Portinari empresta à figura do trabalhador, embora responda a uma visão voltada para o presente, não deixa de ter raízes na bibliografia colocada à sua disposição por Rodolfo Garcia. Na descrição do "estoque" humano necessário ao trabalho nos canaviais, Koster faz referência, de fato, a negros "robustos,

48 WILLIAMS, Daryle. Gustavo Capanema, ministro da Cultura. In: GOMES, Angela de Castro (Org.). Capanema: o ministro e seu ministério. Op. cit., p. 267.

49 GOMES, Angela de Castro. História e historiadores: a política cultural do Estado Novo. Op. cit., p. 191-196; FABRIS, Annateresa. Cândido Portinari. São Paulo: EDUSP, 1996, p. 81-82; MOTA, Carlos Guilherme. Ideologia da cultura brasileira: pontos de partida para uma revisão histórica. Op. cit., p. 32 (grifo meu). Para dados ulteriores, vide: FABRIS, Annateresa. Portinari, pintor social. Op. cit., p. 131-134. 
machos e fêmeas". Varnhagen, por sua vez, lembra que o Brasil devia ao "vigoroso braço" africano o fabrico do açúcar e a cultura do café, principalmente. ${ }^{50}$

O confronto entre as soluções iconográficas buscadas pelo pintor e as fontes historiográficas que lhe foram propostas permite relativizar um argumento como o de Carlos Zilio, que detecta na metodologia de trabalho implementada no conjunto dos ciclos econômicos uma confirmação do caráter historicista do procedimento. ${ }^{51}$ Embora Portinari tenha como ponto de partida fontes documentais e se sirva da observação direta no caso da mineração, deve-se lembrar que, mesmo nos estudos preparatórios, é evidente seu distanciamento da visão global do tema e sua opção por momentos produtivos isolados, nada devedores de um tom épico e celebrativo.

Se não se atentar para a construção iconográfica levada a cabo pelo pintor, na qual há uma dissociação significativa entre o trabalhador e a atividade produtiva, o conjunto dos ciclos econômicos continuará a ser situado sem qualquer problematização no âmbito da ideologia imagética do Estado Novo, caracterizada pela representação da nacionalidade e de seus protótipos: a figura do trabalhador e cenas populares. Maria Amélia Bulhões Garcia, que detecta nesse tipo de produção uma leitura valorativa dos temas populares e do trabalho, sublinhada por um tratamento quase narrativo, percebe, contudo, que não é possível realizar uma interpretação unívoca dessas obras. Se é possível ver nelas a "valorização do trabalho e a visão homogeneizadora e harmonizadora da sociedade promovida pelo Estado", é também possível detectar a valorização das classes trabalhadoras em oposição ao primeiro modelo analítico. 52

A possibilidade de uma dupla leitura vislumbrada pela autora demonstra, na verdade, o caráter complexo de toda produção artística colocada sob a égide da política. Significativa nesse sentido é a resenha que Meyer Schapiro realizou em 1937 do livro Retrato do México, de autoria de Diego Rivera e Bertram Wolfe. Se, de

50 KOSTER, Henry. Viagens ao Nordeste do Brasil. Op. cit., p. 442; VARNHAGEN, Francisco Adolfo de. História geral do Brasil antes de sua separação e independência de Portugal. Belo Horizonte: Itatiaia; São Paulo: EDUSP, 1981, v. 1, p. 223. Se Varnhagen destaca a contribuição do escravo no campo econômico, lembra, contudo, seu papel nocivo no moral, pois lhe atribui a perversão dos costumes "por seus hábitos menos decorosos, seu pouco pudor, e sua tenaz audácia” (p. 225).

51 ZILIO, Carlos. A querela do Brasil. Rio de Janeiro: FUNARTE, 1982, p. 108.

52 GARCIA, Maria Amélia Bulhões. O significado social da atuação dos artistas plásticos Oswaldo Teixeira e Cândido Portinari durante o Estado Novo. Porto Alegre: Instituto de Filosofia e Ciências Humanas/PUCRS, 1983, p. 98-100 (mimeo). 
um lado, o historiador lembrava que as pinturas murais existiam graças ao mecenato de um regime nada subversivo, que abria espaço para uma ideologia revolucionária para que suas imagens cumprissem o papel de fatos subversivos, não deixava, de outro, de reconhecer que elas poderiam ser consideradas os primeiros monumentos importantes de uma arte revolucionária numa sociedade burguesa. ${ }^{53}$

Se esse tipo de consideração for aplicado ao conjunto do Ministério da Educação e Saúde Pública, será necessário, em primeiro lugar, analisar as motivações do mecenato estatal, sobretudo a relação entre novo e passado que está na base das concepções de cultura de Capanema. O novo defendido pelo ministro devia ancorar-se no passado e na tradição, demonstrando ao mesmo tempo ser capaz de fazer vislumbrar um futuro real e plausível. Desse modo, os símbolos do nacional eram "os de um Brasil real que se constrói a partir de dados de um passado histórico concreto". ${ }^{54} \mathrm{O}$ tema dos ciclos econômicos enquadra-se plenamente na configuração de um imaginário nacional no qual as figuras do moderno respondem a uma dupla tarefa: produzir a um só tempo o futuro e a tradição. A história da construção da riqueza pública, à qual Capanema se remete para simbolizar as capacidades do Brasil graças ao poder modernizador do Estado, não é uma escolha casual. Insere-se no âmbito de uma política cultural que valoriza símbolos atemporais como a natureza, a terra, a vida agrária enquanto elementos constitutivos da identidade nacional. Esses símbolos, alicerçados em práticas materiais, não só asseguram uma fisionomia à nação como lhe garantem um sentido histórico preciso, expresso tanto na permanência de um cerne do passado quanto na possibilidade deste deslocar-se no tempo e atingir o presente. ${ }^{55}$

Esse sentido dinâmico faz falta ao conjunto de Portinari. Se há uma "continuidade" na representação das figuras do trabalho, ela diz respeito não à atividade econômica em si, mas à configuração de uma imagem do trabalhador que nega todo dinamismo e toda visão positiva do elo que liga o passado ao presente. Estático e ensimesmado, o trabalhador de Portinari é uma figura reificada e

53 NEGRI, Antonello. Il realismo: dagli anni trenta agli anni ottanta. Op. cit., p. 16-17.

54 LISSOVSKY, Maurício; SÁ, Paulo Sérgio Moraes de. O novo em construção: o edifício-sede do Ministério da Educação e Saúde e a disputa do espaço arquitetural nos anos 1930. Op. cit., p. 65. Vide também: GORELIK, Adrián. Brasília: o museu da vanguarda, 1950 e 1960. Margens, Belo Horizonte, n. 4, p. 56-58, dez. 2003.

55 FABRIS, Annateresa. Um símbolo moderno. In: Fragmentos urbanos: representações culturais. São Paulo: Studio Nobel, 2000, p. 172; GOMES, Angela de Castro. História e historiadores: a política cultural do Estado Novo. Op. cit., p. 160-161. 
destituída de identidade. Seu anonimato, antes de evocar a idéia de uma totalidade abrangente (povo ou nação, por exemplo), evoca o processo de mercantilização do trabalho e, logo, a cisão entre o trabalhador e a atividade produtiva, simbolicamente representada pelos dois recursos já destacados: a estrutura espelhada e o desdobramento da mesma figura em vários momentos da produção.

Fiel aos pressupostos que regiam sua representação do trabalhador rural na década de 1930, Portinari parece ter encontrado um reforço para sua concepção heróica numa observação de Antonil. $\mathrm{O}$ autor considerava os escravos africanos "as mãos e os pés do senhor de engenho"56 e atribuía à sua presença o pleno desenvolvimento da atividade agrária. É logo essa idéia que o conjunto dos ciclos econômicos realça ao conferir magnitude aos elementos do corpo destacados por Antonil. As gigantescas figuras de trabalhador do conjunto ministerial enlaçam-se com as de Mestiço (1934) e Lavrador (1934), pois, como elas, são regidas por um duplo registro.

O caráter estático de sua pose contrasta sempre com seu gigantismo, podendo ser visto como índice de uma dissociação profunda entre o esforço despendido pelos trabalhadores e o resultado concreto de sua labuta, sem a qual não existiria o sistema econômico alicerçado nas grandes plantações tropicais. Verdadeiras "máquinas de trabalho afeitas a toda sorte de esforço", 57 as figuras de trabalhadores propostas por Portinari estabelecem uma continuidade crítica entre passado e presente, pois têm como elemento comum a apresentação da atividade produtiva como alienação. Se parece ser demasiado aplicar a essa concepção o adjetivo de revolucionária - tal como havia feito Schapiro com o muralismo mexicano -, é possível, contudo, considerá-la crítica, afastando do pintor a pecha de "artista oficial" que ainda hoje continua a perseguilo.

56 ANTONIL. André João. Cultura e opulência do Brasil. Op. cit., p. 89.

57 GOULART, Maurício. O problema da mão de obra: o escravo africano. In: HOLANDA, Sérgio Buarque de (Org.). História geral da civilização brasileira. São Paulo: Difusão Européia do Livro, 1960, t. 1, v. 2, p. 184. 